\title{
Bringing Home the Crisis: How US Evening News Framed the 2011 Japan Nuclear Crisis
}

\section{Nicholas T. Iannarino*, Shari R. Veil** and Alfred J. Cotton III****}

*Department of Language, Culture, and Communication, University of Michigan-Dearborn, 3036 CASL Building, 4901 Evergreen Road, Dearborn, MI 48128. E-mail: iannarnt@umich.edu

**Risk Sciences Division, College of Communication and Information, University of Kentucky, 235 Grehan Building, Lexington, KY 40506-0224. E-mail: shari.veil@uky.edu

***College of Communication and Information, University of Kentucky, 308 Lucille Little Library, Lexington, KY 40506-0224. E-mail: alfred.cotton@uky.edu

Crisis communication scholars have used framing theory to argue that how the media characterizes varying aspects of a crisis can influence the public's perception of the event. While much of the crisis-framing research has been content analysis-driven, providing numbers and percentages of news stories that fit a certain story type, it is also important to examine how shifts in public opinion and policy may be indicative of and influenced by the ongoing discourse that news outlets use to characterize international crises. In this study, we use inductive analysis to describe the frames used by US evening network news to characterize the 2011 Japan nuclear crisis and outline how this coverage may have shaped and reflected public opinion and policy in the US during and following the crisis.

\section{Introduction}

\footnotetext{
risis is defined as a 'sense of threat, urgency, and destruction, often on a monumental scale' (Seeger, Sellnow, \& Ulmer, 2003, 4). For communities directly affected by a large-scale crisis, the effects can reverberate for years or even decades as the public struggles to make sense of the crisis, address the lingering risks caused by the event and adapt to the new normal of life after the incident. Recently, however, technological advances allowing for increased media access and dissemination have augmented the immediate and farreaching effects of a crisis. Within minutes of a major disaster, media channels broadcast images and begin framing various aspects of the crisis in their coverage to make the incident salient to audiences. Regardless of their physical proximity, individuals in the community and around the globe can now experience the cognitive and emotional effects of witnessing an incident as it unfolds in the media.
}

Media are considered the 'most important information path' during a crisis event (Larsson, 2010, 716). Despite the growing popularity of social media as a forum for crisis communication, media consumers are more likely to share crisis information from traditional media sources because of its higher perceived credibility (Utz, Schultz, \& Glocka, 2013). Television, specifically, is the most common medium used in times of risk and crisis because of its ability to deliver immediate information with visual aids (Heath \& O'Hair, 2009). While the Internet is now the second most popular news platform, with 39\% of Americans receiving their news online, television remains the most widely used news medium, with $55 \%$ of Americans turning to television as their source of information (Pew Research Center, 2012). Therefore, it is important to explore how television news coverage can play a prominent role in explaining crisis events to make them more meaningful for audiences, especially when those events are complex or happen on the other side of the world. 
Crisis communication scholars have used framing theory to argue that how the media characterizes varying aspects of a crisis can influence the public's perception of the event (Sellnow \& Seeger, 2013). Several news frames, or core aspects of a story that are selected and advanced by the media to characterize and make sense of an event, have been previously identified as occurring commonly in US news coverage (An \& Gower, 2009; Houston, Pfefferbaum, \& Rosenholtz, 2012). For example, across 11 US natural disasters between 2000 and 2010, five primary frames characterized national news coverage. These were labelled environment, human interest and economic, which involved the natural, emotional and financial consequences of the crisis respectively; political, which addressed the actions of government leaders and their policies; and criminal, which involved crisis-related legal incidents and investigations (Houston et al., 2012). An et al. (2009) also examined national news coverage of organizational crises and found that prominent frames included attribution of responsibility, which held either an individual or an organization accountable for the crisis's cause or solution; conflict, which reflected disagreement among individuals or organizations following the incident; and morality, which considered the event and the behaviour of those responsible for the crisis through an ethical lens. These frames have largely been identified through content analysis-driven studies, which indicate what types of stories are covered by the media. However, knowing that a certain percentage of news coverage is devoted to particular frames does little to explain how the content of these stories could influence how audiences make sense of a crisis as part of a larger social discourse.

Specific to this study, Gamson and Modigliani (1989) identified seven frames used in US media discourse to characterize issues related to nuclear power. However, they also argued that this ongoing coverage both reflected and shaped public opinion of nuclear energy during that time. In the 1950s, TV network news and other media framed nuclear power as a necessary and inevitable tool for human progress because of its potential to create economic growth and peace around the world. Progress remained unopposed in media and public discourse until the 1970s, when a widespread energy crisis resulted in a second major pronuclear frame: achieving energy independence in the United States. Increased proliferation of nuclear weapons and growing public concern about the safety of nuclear reactors led to the introduction of public accountability frames, which characterized nuclear corporations as prioritizing their own interests above public safety and transparency. Frames also indicated resignation to the runaway nature of nuclear power, a technological monster that humans have created and cannot stop, a 'time bomb waiting to explode'.Two other frames, soft paths, or environmental alternatives to nuclear energy, and the cost ineffectiveness of nuclear power were identified but not prominent in media discourse (Gamson \& Modigliani, 1989).

Clear anti-nuclear frames were rare in the national media until the nuclear crises at Three Mile Island and Chernobyl, which accelerated a shift from progress to runaway as the most prominent frame. Fear surrounding the delayed and invisible effects of radiation and a belief that nuclear officials were overestimating their ability to manage the crises comprised the media's fatalistic frame of nuclear power as an out-of-control technology that would inevitably cause future US crises. Public accountability was also prominent in framing the nuclear industry as generally incompetent and deceptive in misleading the public to protect their image. Additionally, a new frame called devil's bargain emerged as progress and runaway frames began occurring sequentially to produce ambivalence towards nuclear energy. Through survey research, Gamson and Modigliani (1989) found that this media discourse, particularly the lack of a clear progress frame following Chernobyl, contributed to and reflected the public's widespread ambivalence towards nuclear power. During peak media coverage of nuclear energy issues, for example, public support for the industry dipped, only to return to previous levels as the media shifted their focus to another topic (Gamson \& Modigliani, 1989). Thus, people who closely follow media and governmental discourse are likely to develop perceptions consistent with the most prominent frames (Lim \& Seo, 2009).

In this study, we use inductive analysis to describe how news media contribute to ongoing discourse about nuclear power through the framing of a recent nuclear disaster. We also question how the characterization of this incident may have influenced and reflected changes in media consumers' perceptions and public policy following the crisis. First, we provide an overview of crisisframing literature and describe the process of data collection and analysis. We then describe the prominent frames that characterized US broadcast evening news coverage of the 2011 Japan nuclear crisis. Finally, we discuss the implications for how these frames may have shaped and reflected public opinion and policy based on crisis-framing theory.

\section{News framing theory in crises}

During international crisis events, media and government discourse and public opinion interact with one another as parallel systems, influencing and reflecting one another to produce meaning over time (Lim et al., 2009). During the coverage of complex and international crises, news media actively aid audiences in interpreting larger discourse by defining the meaning, value and causes of events; connecting incidents as they unfold; and offering moral judgments in a way that 
demonstrates their perspective (Entman, 1993; Littlefield \& Quenette, 2007; Ryan, Carragee, \& Meinhofer, 2001). Media frames, which comprise the core of interpretive news packages (Gamson \& Modigliani, 1989), give meaning to events, eliciting behavioural, cognitive, and affective responses from audiences (Van Gorp, 2007). The media's 'selection, emphasis, and exclusion' (Ryan et al., 2001, 176) of the symbolic devices that characterize news discourse constitutes framing's function as 'a central organizing idea for making sense of relevant events and suggesting what is at issue' (Gamson, 1989, 157).

Because media are often considered the clearest indicator of the general issue culture (Gamson \& Modigliani, 1989), the ways in which news frames crisis events provide an essential context for interpreting the public's perceptions of the incidents and their ramifications (Miller \& Riechert, 2001). Walters and Hornig $(1993,220)$ even argued that news helps determine 'how people cope with and behave in a world in crisis'. When audiences focus on the cues provided by the media to construct their own perceptions, attitudes, judgments, knowledge and behaviours about disaster events, issues and the individuals involved, a crisis-framing effect occurs (Coombs \& Holladay, 2010).

\subsection{Frame competition in crisis management}

Following a crisis, status-quo players and change advocates appear in the mass media to engage in 'framing contests' (Seeger et al., 2003), where actors' interpretations of the event and visions of future policies compete for public and political support (Boin, Hart, \& McConnell, 2009). For example, international crises often raise conflicting interpretations domestically regarding the likelihood that similar events may occur, how prepared organizations are to deal with these crises, and options for reducing potential risks (Zoeteman, Kersten, Vos, van de Voort, \& Ale, 2010). Contestants may also characterize the crisis as an unfortunate and uncontrollable incident, where wellmeaning policy-makers should be absolved and existing policies left intact, or as an opportunity to assign blame to existing policies, individuals or organizations for failing to prevent a foreseeable and controllable calamity (Boin et al., 2009). During coverage of Hurricane Katrina, for example, instead of focusing on the hurricane as the cause of the crisis, newspapers directed the public to assign blame and responsibility to authorities for their ineffective crisis response (Littlefield et al., 2007). When individuals or organizations are blamed for the crisis, they must choose to reject, deflect, diffuse or accept responsibility for the incident to attempt to avoid negative political consequences (Boin et al., 2009). However, if a crisis is widely believed to be preventable, if the actors have been in power for a long time, and if those responsible have not gained a wealth of credibility or good press before the crisis, oppositional forces will likely be more successful in gaining public and political support in framing contests (Boin et al., 2009).

Additionally, media coverage is only likely to support crisis managers' frames if their communication is perceived as credible (Masters \& Hart, 2012). When a crisis occurs, the public expects actors to quickly and persuasively answer questions about how severe the situation is, how it occurred, who or what is to be held responsible, and what needs to be done to alleviate it (Boin et al., 2009). Conversely, if actors were insufficiently transparent or purposely withheld information before or at the start of a crisis, additional waves of negative media attention and decreased trust in authorities will likely occur (Zoeteman et al., 2010). For example, after China refused to cooperate with the international community in managing the 2003 severe acute respiratory syndrome (SARS) crisis, Western news sources began contradicting statements made by Chinese officials with those of the World Health Organization (Buus \& Olsson, 2006).

Despite an organization's attempts to frame their crisis response favourably, news frames can heavily influence public opinion about crisis actors' performance and external image (Strömbäck \& Nord, 2006). In an experimental framing effects study, news frames that evoked anger towards an organization's intentional wrongdoing caused audiences to process less information and to possess more negative attitudes towards those responsible (Kim \& Cameron, 2011). Placing an emphasis on an organization's intentionality, immorality and unethical behaviour in causing a crisis affects audiences' moral judgment and thus elicits more blame (An, 2011). Likewise, when the Tokyo Electric Power Company (TEPCO) was framed in traditional and social media as being responsible for the 2011 Japan nuclear crisis, audiences were more likely to experience anger towards TEPCO and share more negative messages about the company's diminished reputation than when they were framed as victims of the crisis (Utz et al., 2013). However, stories that employ human interest frames, demonstrate sadness for crisis victims, or hold an organization responsible for a crisis instead of an individual can result in increased audience empathy (Cho \& Gower, 2006), increased message processing (Kim et al., 2011), and less anger and blame (An, 2011).

\subsection{News production rituals}

In addition to producing meaning, journalists are consumers of the same media output that is framed for the public (Gamson \& Modigliani, 1989). During crisis coverage, journalists must first decide what constitutes a crisis event and what role they will play in its coverage. Media managers define calamity events as surprising 
incidents that demand a quick response and swift decision making and that have the capacity to challenge organizational values and routines for covering similar events in the future (Olsson, 2010). For example, international nuclear disasters often gain intense media attention because they are typically unexpected and their magnitude can usually be felt around the world (Zoeteman et al., 2010). Media managers believe their role in crisis coverage transcends simple information dissemination by also attempting to fulfil the therapeutic ritual of providing their audience with immediacy, comfort, reassurance and understanding of the event (Riegert \& Olsson, 2007).

During crises when events change rapidly, news frames are typically dynamic rather than static (Li, 2007). These frames must shift in accordance with the audience's understanding of the event as it evolves in order for the media to remain relevant in the historical drama (Olsson, 2010; Riegert et al., 2007). When a story's temporal and spatial frames are intermittently shifted, the crisis event's salience in the news and among the public is increased (Muschert \& Carr, 2006). Additionally, crises that are unanticipated and generate risk usually cause uncertainty, which audiences attempt to reduce at the start of the incident by seeking media information to gain a better understanding of the event (Spence, Westerman, Skalski, Seeger, Sellnow, \& Ulmer, 2006). As such, fluctuating frames initially function as a source for information, clarification and uncertainty reduction; later as a tool for immediate sensemaking; and finally as an outlet for understanding long-term implications (Li, 2007). Journalists must also select their sources in crisis coverage to determine "not only who will be heard, but also what will be heard'. For example, 'Witnesses, experts, victims, spokespersons, and officials are integral components of the newsgathering process in a disaster setting' (Walters et al., 1993, 221). When 'expert' voices are marginalized by journalists who emphasize the role of lay parties, the dissemination of accurate information about the scientific and technical aspects of a crisis does not occur, which may lead to public confusion about the disaster and its aftermath (Cohen, Vijaykumar, Wray, \& Karamehic-Muratovic, 2008; Walters et al., 1993).

\subsection{Culturally discrepant news framing}

Media frames become the building blocks of culture and reality because they are 'socially shared and persistent over time [and] work symbolically to meaningfully structure the social world' (Reese, 2001, 11)'. Despite the current belief that we 'live in a global information age with media systems that transcend national borders', a media outlet's country of origin may cause 'different aspects or attributes of the same issue' to be presented through different frames (Luther
\& Zhou, 2005; Tian \& Stewart, 2005, 299). In fact, the same event may be understood differently by international audiences depending on the frames used to define it (Tian et al., 2005). Culturally discrepant news framing reflects different nations' divergent media values and roles, larger cultural themes, economic interests, political contexts and current relationships with the nations affected by the crisis (Feng, Brewer, \& Ley, 2012). For example, although coverage of the SARS outbreaks (Luther et al., 2005) and the 2008 Chinese baby formula recall (Feng etal., 2012) by major Western and Chinese newspapers emphasized many of the same frames, Western news criticized Chinese systems for failing to manage the crises to a greater degree than the Chinese news, which focused more on positive initiatives undertaken by leaders. How domestic news characterizes crises in other parts of the world can be particularly important because these incidents are not directly experienced and limited information is available from other sources.

\section{Crisis context}

To analyse how the news framed a recent nuclear crisis, we looked at the specific context of a disaster that occurred on 11 March 2011 when an 8.9-magnitude earthquake hit the east coast of Japan, generating a $30-\mathrm{ft}$ wall of water that swept away homes, buildings, cars and thousands of lives (CNN, 2011a). The earthquake and tsunami also triggered meltdowns of three reactors at the Fukushima Daiichi nuclear power plant, releasing radioactive material into the air and ocean (CNN, 2011b). In the United States, live news broadcasts broke into regular programming to report on the cascading crisis events. During the weeks that followed, news agencies continued to follow the storyline as both the death toll and radiation levels rose.

In this study, we specifically examine the nuclear aspect of the crisis because, while triggered by a series of natural disasters, the nuclear concerns increased the crisis impact and added considerations of organizational responsibility, which altered the expectations of the crisis response. Like Gamson and Modigliani (1989), we are not arguing that changes in media discourse cause direct changes in public opinion, but rather we are attempting to understand the shift in US public opinion and policy regarding the 2011 Japanese nuclear crisis within the context of ongoing media discourse related to nuclear power.

\section{Methods}

The Digital Content Analysis (DCA) Lab, housed within a college of communication at a south-eastern university, perpetually records 20 US network and cable television channels. The system provides video streams 
and programme transcripts of half-hour blocks of broadcasted content for all digital captures, resulting in 480 hours of broadcast data each day. This content is accessible through a search engine archive known as COMMTV, which can be used to identify, track and analyse specific media content related to news events.

We used this database to collect video artefacts and transcripts between 11 March and 11 April 2011. Because discussion began to taper in the US news media around 4 weeks after the initial earthquake, these dates best represent the initial and evolving concerns over nuclear safety in Japan and the United States. Our search terms paired 'Japan' and its syntactic variations (e.g., 'Japanese', 'Japan's', etc.) with 'radiation', 'nuclear', 'contamination' and 'exposure', and the syntactic variations of these terms. The database was primed only to include transcripts where a pair of search terms appeared within 200 words of one another, so as to limit the occurrence of irrelevant content.

The DCA Lab stores video and transcripts from seven network and 13 cable channels. For this analysis, we narrowed our focus to US network broadcasts of evening news content airing between 18.00 and 20.00 hours EST on $A B C, C B S, N B C$ and PBS. Evening news programmes on the 'big three' television networks (i.e., $A B C, C B S$ and $N B C$ ) average a combined 21.6 million viewers a night. US primetime cable news coverage, meanwhile, attracts only 3.2 million viewers, while morning network news programmes average 12.4 million (Guskin, Rosenstiel, \& Moore, 2011). Thus, we chose to analyse evening network news programmes based on their comparative average viewership, widespread proliferation, and status as a top news platform in the United States (Pew Research Center, 2012).

Our initial search revealed 96 videos and transcripts of network evening news coverage. Three items were omitted for not containing content relevant to the Fukushima nuclear crisis and were only initially included as a result of arbitrary word combinations. We were left with 93 videos and transcripts representing 46.5 hours of evening network news coverage. The distribution of included programmes across the networks varied moderately, with 29 videos and transcripts culled from NBC, 25 from PBS, 21 from $A B C$ and 18 from CBS.

\subsection{Coding process}

Previous framing analyses of crisis events have been conducted both inductively to determine what frames emerged in the crisis coverage (Feng et al., 2012; Gamson \& Modigliani, 1989; Joye, 2010; Littlefield et al., 2007; Tian et al., 2005) and deductively using frames that have occurred commonly in news coverage (An et al., 2009; Li, 2007; Luther et al., 2005; Muschert et al., 2006; Walters et al., 1993). In this study, we were inter- ested in describing the central themes that were specific to US network evening news coverage of the 2011 Japan nuclear crisis and categorizing these themes into the larger core frames that fundamentally characterized this event. Thus, we conducted an inductive analysis of evening network news transcripts using the constant comparative method (Butler-Kisber, 2010). Two coders individually analysed the data in its entirety to perform open coding, searching inductively for as many commonalities that emerged from the data's events, commentary and actions (Strauss \& Corbin, 1998). Both coders then met to discuss and refine the open codes and place them into larger axial categories, collapsing, comparing and integrating them around specific points of intersection until we identified the 14 themes that best captured the variation in the data set. Two of the authors then individually applied the 14 themes to $20 \%$ (19 transcripts) of the sample by randomly selecting every fifth transcript to deductively gauge the consistency and trustworthiness of the themes with the data set and the two coders' interpretations. After another group discussion, the remaining transcripts were coded separately; Coder 1 analysed 38 transcripts and coder 2 analysed 36. After coding all 93 transcripts, the group reached consensus that the thematic categories were saturated and thus could not be broken down or added to any further (Butler-Kisber, 2010). The coders then conducted a final read of the transcripts to group the 14 emergent themes into the four larger core frames that best characterized the crisis coverage (Strauss et al., 1998).

In keeping with other exemplar inductive analyses (e.g., Buus et al., 2006; Harry, Sturgis, \& Klingner, 2005), we did not calculate an intercoder reliability score (Neuendorf, 2002). Instead, we relied on multiple intensive group discussions between each round of data analysis to assess discrepancies, deal with conflicting interpretations, clarify the appropriateness and consistency of emergent themes, and reach consensus to ensure that both coders remained consistent in their analysis. Based on these discussions, we wrote brief descriptions of the four frames and their themes to best represent the coverage as it occurred. We also selected events, commentary and actions from the coverage to include in the findings that best represented the four frames and their themes.

\section{Findings}

Analysis of the coverage resulted in four core frames that characterized US network evening news discourse of the crisis: (1) uncertainty and anxiety; (2) bringing it home; (3) heroes and villains; and (4) cancer and contamination. Later, we describe the four frames and their central themes by citing specific examples from the news broadcast coverage. 


\subsection{Uncertainty and anxiety}

This frame reflected the network news reporters' attempts to create meaning of the unpredictable nuclear crisis, speculate about the possible immediate outcomes and recovery efforts at the damaged Fukushima plant, and contextualize a complex situation by drawing historical comparisons with previous nuclear crises. This frame also characterized the response of Japanese citizens to the nuclear crisis, particularly anxiety and isolation resulting from radiation fears. Three central themes described this core frame: (1) uncertain severity and desperation; (2) crisis comparisons; and (3) public anxiety and abandonment.

\subsubsection{Uncertain severity and desperation}

Speculation about the severity and danger of a 'worst case scenario' varied at different points during the coverage. The only frame that remained consistent throughout the coverage of the immediate nuclear crisis at Fukushima was that the narrative itself was unpredictable. On 28 March, ABC observed, 'it certainly seems the story shifts day by day'. Stories centred on Fukushima workers' 'desperate attempts' to cool the reactor primarily through the infusion of water, and it appeared that nearly every complication at Fukushima could be averted if workers could pull off a last-second, seemingly improbable and risky solution. Each strategy was described as a 'drastic step', a 'last-ditch effort' or the 'last big gamble'. Initial efforts to cool the reactors were framed as impractical, improvised and desperate like 'using a squirt gun to put out a forest fire' (ABC, 17 March). The alternative - multiple nuclear meltdowns was believed to be so devastating that workers had no choice but to continue.

\subsubsection{Crisis comparisons}

Network news reporters and expert guests attempted to make sense of the complicated, science-heavy and threatening situation at Fukushima through metaphorical language. Coverage in this theme frequently assessed the preliminary similarities and differences between the Fukushima crisis and other well-known nuclear calamities - Chernobyl, Three Mile Island, and to a lesser extent, Japan's previous experience with widespread radiation in Hiroshima and Nagasaki at the end of World War II. While experts on $A B C$ believed the total amount of radiation released could equal or surpass the Chernobyl accident, NBC argued that such an outcome was unlikely. CBS and NBC broadcasted packages filmed in the radioactive ruins of Chernobyl, still desolate 25 years after the disaster. On 18 March, CBS questioned whether the timetable of recovery or inhabitability would rival that of Chernobyl: 'From the initial panic at Chernobyl to the lack of a permanent solution 25 years later, a lesson in just how hard it is to put the nuclear genie back in the bottle'.

\subsubsection{Public anxiety and abandonment}

Japanese citizens were generally characterized as being tense about the crisis at Fukushima. This overall feeling of uneasiness was a product of more specific sentiments of anxiety, frustration, uncertainty and scepticism: 'It is frightening. I look at my children and worry' (CBS, 18 March). Network coverage also frequently described the streets of Tokyo as deserted, largely because of a growing exodus of Japanese citizens particularly precautious families with small children. On 16 March, CBS stated that the Tokyo airports were filled with a growing number of citizens attempting to take flight. Contrasted with the desolate Tokyo rush hour trains, the inter-city bullet trains were described as 'absolutely packed ... moving tens of thousands of people to the south, where they think it's safe' (PBS, 17 March). Despite the mass departure, Tokyo was reported to be running out of supplies:

We found stores running out of everything, a sign of growing anxieties. [Tokyo resident]: 'Nothing. No water, no food, so l'm going back to my hometown'. Other parts of this normally bustling city looked like a ghost town. Fear and a shortage of gas are keeping people off the streets (NBC, 16 March).

The situation did not improve later in the week. On 17 March, ABC reported that 140,000 people lived in the 12-19-mile ring that surrounded the plant. Many of them remained helpless: 'Cut off from the outside world, conditions are beginning to deteriorate'. The search for survivors and collection of dead bodies within the largely desolate containment zone was also hampered.All four networks reported on 18 March that over 100 elderly people were discovered abandoned in a hospital six miles from the Fukushima complex, some of them comatose. On 30 March, NBC described the containment zone littered with lifeless bodies as 'a ghost town that [became] that much more unsettling'.

\subsection{Bringing it home}

In an attempt to localize coverage of the events at Fukushima, news broadcasters characterized the crisis as having the potential to affect the United States in a number of ways. Themes included: (1) reassessing the 'nuclear renaissance'; (2) calming radiation concerns; and (3) Americans abroad.

\subsubsection{Reassessing the 'nuclear renaissance'}

The most common theme within this frame focused on the safety of the 104 nuclear reactors in the 
United States. This theme was present consistently throughout the month of coverage. Since taking office, President Obama had pushed for an increase in America's use of nuclear power to lower the country's dependence on fossil fuels (Jones, 2010). However, the Fukushima disaster emboldened nuclear critics, led foreign nations to reassess their own nuclear programmes, and caused US politicians and citizens to express concern over the safety of nuclear energy. The disaster in Japan provided fuel for critics' arguments that flaws in the design of these plants cannot account for Mother Nature and human fallibility. Congressman Henry Waxman argued that the crippled Japanese reactors were identical to those used at 16 plants across the United States. When asked if American nuclear reactors are safe, he stated, 'No, I can't reach that conclusion, nor can anybody at this point. The industry tells us to relax, we're okay. I wouldn't take anything like that at face value' (ABC, 16 March). Thus, this frame's most prominent theme was not the dangers directly associated with Fukushima's crisis, but the potential for a similar event to occur in the United States.

\subsubsection{Calming concerns}

The second theme focused on concerns of radiation reaching the United States. Analysts used nuclear experts and medical authorities to highlight the precautions people should and should not take, the potential health effects of radiation exposure and issues pertaining to food safety. However, reporters and their expert guests frequently reassured audiences that there was nothing to worry about. For example, on 14 March, 3 days into the crisis, CBS had what they called a 'reality check', addressing concerns surrounding the detection of radiation that had spread to the United States:

Radiation is all around us, even inside of us, all the time and it's perfectly natural and safe. To illustrate this point, we got hold of this Geiger counter. As you can see [...] there is always background radiation. Check this out. I'm going to put it up against bananas. You can see it goes up just a little bit. For the most dramatic reading, here is what happens when we go up to this monument. It's made out of granite. Granite is radioactive but perfectly safe ... (CBS, 14 March)

News media also reported that many individuals purchased large quantities of iodine tablets. Experts argued that iodine pills are meant only for radiation exposure and are unhealthy if taken without warrant. Reports concluded that Americans' money would be better spent on donations.

\subsubsection{Americans abroad}

Another theme made salient to American audiences was the fate of Americans in Japan, both within and outside the evacuation zone. The United States has service members stationed at military bases in Japan and on aircraft carriers off the Japanese shore.There are also civilian Americans living, working and vacationing in Japan. Initially, reporters focused on the US government's urging that all Americans at least leave the evacuation zone. Later coverage focused on the emotions associated with Americans staying behind:'One husband is leaving his job early to go back to North Carolina. Another family, quite poignant, the father staying here to work, the little boys blowing him kisses' (ABC, 16 March).

\subsection{Heroes and villains}

Coverage also characterized the crisis as being caused and managed by actors who were categorized into two dichotomous groups based on their perceived competence and values: heroes and villains. Themes within this frame emphasized the contrasting protection measures issued by Japan and the United States, portraying the US government as protective guardians and the Japanese government as untrustworthy. Themes also characterized workers at the Fukushima power plant as heroes for staying behind to prevent another meltdown and TEPCO as villains for not managing the response effectively. Finally, the Japanese people were characterized as honourable for their ability to retain a shared sense of sacrifice in the midst of tumult.

\subsubsection{America as watchdog and guardian}

Stories were often characterized within the context of how much assistance the United States was providing to bring the nuclear crisis under control. ABC's March 18 broadcast, for example, described the US role in assisting Japan: 'Tonight the U.S. continues to help the Japanese try to get power up and running to get the cooling pumps working again ... but once power is on, standing by are five huge high pressure water pumps from the U.S.' Coverage portrayed the United States as fulfilling the role of heroic guardians, especially considering little attention was paid to the role other nations played in the crisis response.

News reports also characterized the United States as possessing a more enlightened perspective on disaster relief and as having a better grip on the situation than the Japanese. PBS contrasted the American and Japanese approaches to evacuation: 'I guess the thing I'm struck by is the response, the Japanese response against the American response, the different political styles ... our government has probably been a little more accurate from what I can see'. This portrayal of American 
government as more knowledgeable and 'accurate' in terms of appropriate evacuation and containment measures and regarding the amount and severity of radiation release was present among the other networks as well.

\subsubsection{Loss of trust in the Japanese government}

US broadcast news was critical of Japanese officials' management of the crisis. Japanese government was characterized as initially resistant to accept assistance from outside nations, as failing to express concern and provide sufficient information, as underestimating the severity of the situation, and as neglecting to take appropriate and timely action. On March 17, Yuki Tatsumi, a specialist in international politics and security, stated on PBS: 'I don't think the Japanese government has a very good grip on the situation right now, and $I$ think the fundamental problem about this current government has been that there has been a series of questions even before this disaster hit Japan about their capability for frankly managing crises'. Japanese citizens had also reportedly lost faith in the Japanese government, particularly in their failure to 'divulge the full extent of what's happened and what the danger may be' (ABC, 12 March). CBS reported on 16 March that 'the fallout from Japan's worst nuclear accident is growing panic and suspicion that the government and TEPCO ... are not telling the whole truth'.

\subsubsection{Heroic workers}

Another prominent theme emphasized the heroism of, complications faced by, and tactics employed by Fukushima workers to prevent further meltdown. On 24 March, US networks reported that three workers were exposed to radiation when radioactive water seeped into their boots and severely burned their skin. Although the workers were expected to heal, network news used the incident to demonstrate the danger of the workers' heroic efforts in staying behind to manage the crisis despite many significant complications. TEPCO came under fire for not issuing proper protective gear because their boots merely came up to workers' ankles.

\subsubsection{Inept leaders}

News broadcasts unleashed considerable criticism of TEPCO concerning possible oversights in their disaster preparedness, particularly in regard to faulty equipment and facility design, neglecting to adhere to safety standards, previously falsifying safety reports and frequently mismanaging public relations. TEPCO also issued overblown information about the severity of a radiation leak on 27 March, causing workers to be evacuated from the
Fukushima complex. Nuclear experts perceived the receipt of unreliable and inconsistent information as 'inhibiting an effective crisis response' (CBS, 16 March). NBC characterized TEPCO's mismanagement of this situation as providing additional evidence that the overall crisis had been mishandled in terms of both prevention and response: "It was the second apology in as many days, and just the most recent example of late or flat out erroneous information coming from the owners of Japan's stricken nuclear power plant'.

\subsubsection{Resiliency of the Japanese people}

Like the selflessness and heroism associated with the Fukushima workers, the Japanese population was characterized by US network news as displaying a uniquely brave and stoic response to an unthinkable sequence of disasters. NBC interviewed a patron at a Tokyo market on March 20 who felt she had a duty to purchase food that tested positive for radiation 'to help farmers'. On April 5, CBS spoke with a woman who was willing to sacrifice fresh fish because 'we can always eat dried ones that were caught last year'. On 17 March, ABC reported that doctors and nurses remained behind to care for elderly residents at a nursing home 15 miles from the crippled nuclear plant after evacuation teams refused to remove them. The cultural collectivism was often characterized in US network news as a uniquely Japanese sense of shared sacrifice. On 17 March, NBC interviewed patrons at a restaurant who were out of fuel, trapped if radiation were to blow through the area: 'There's no complaining though. Instead just a quiet determination'.

\subsection{Cancer and contamination}

An emphasis on health concerns for Japanese citizens also emerged consistently across the coverage. This frame included themes on Japanese (1) vulnerable populations; (2) food and water safety; and (3) 'background' radiation.

\subsubsection{Vulnerable populations}

Health-related broadcasts focused primarily on the risk of cancer for vulnerable populations such as young children and infants. US networks provided explanations for why children are particularly susceptible to thyroid damage from radiation. Those who lived and worked in the evacuation zone were identified as the most vulnerable. Several nuclear experts noted that the radiation levels absorbed by Fukushima workers could be lethal over a short period of time, in some cases after 30 days of continuous exposure. An expert on radiological research stated on PBS on March 28 that he was 'very concerned about the long-term issues for the 
radiation workers. I think we could be looking at some serious injuries'.

\subsubsection{Food and water safety}

Concern for contaminated food emerged during the second week of the Fukushima crisis, around 19 March, when traces of radiation appeared in Japanese milk and leafy vegetables 90 miles from the damaged reactors. On March 21, elevated levels of radioactive iodine and cesium were reported in Tokyo's tap water, measuring at twice the level considered safe for children and infants. CBS reported on 23 March that Japanese officials provided 250,000 bottles of water to families of the 80,000 infants under age 1 in Tokyo. Even after the regional governor declared Tokyo's tap water 'delicious and safe for all' on 24 March, US network news coverage portrayed most Japanese mothers as sceptical: 'Ten or 20 years down the road, what's going to happen to me and my baby?' (NBC, 24 March).

Much of the coverage asserted that there was a difference between detection of radiation and actual danger. Despite these reassurances, Japanese farmers, restaurants and food vendors experienced a dramatic drop in business almost immediately after initial detection. At least 25 countries restricted imports of Japanese milk and produce. Network news coverage suggested that attempts to convince customers that not everything grown near the Fukushima plant was radioactive were futile.

\subsubsection{Background radiation}

Also salient in broadcasts was the act of screening areas surrounding the Fukushima complex for radiation contamination. In the first week of the crisis, broadcasts frequently alluded to the presence of Geiger counters, handheld scanners and head-to-toe protective radiation suits used by radiation experts to screen tens of thousands of citizens for the presence of contamination, particularly those evacuated from the containment zone or nearby when the building housing one of the troubled reactors exploded. On 6 April, ABC reported that, among schoolchildren at the start of the new academic year, 'Geiger counters were almost as common as lunch boxes'.

For the most part, however, detected radiation levels were not characterized as harmful to the short-term health of general populations. Four days after workers at the Fukushima plant were forced to vent radioactive vapour to prevent a reactor meltdown, CBS reported that individuals just outside the containment zone would not even receive doses comparable with a chest $x$-ray. Radiation was often detected at "background levels' in major Japanese cities, particularly Tokyo, meaning that the presence of nuclear contamination was elevated, but not high enough to pose a health threat.
Fundamentally, US network evening news coverage characterized the events associated with the 2011 Japanese nuclear crisis through four core frames: (1) uncertainty and anxiety, which characterized the nuclear incident itself as unpredictable, portrayed the desperation of response efforts, contextualized the crisis by comparing it with past nuclear disasters, and described feelings of isolation in the containment zone; (2) bringing it home, which localized coverage to characterize the crisis as having the potential to affect the United States by discussing the future of US nuclear power, quelling concerns of radiation dangers, and issuing sympathy for American citizens in Japan; (3) heroes and villains, which dichotomized the competence and values of US and Japanese management strategies, analysed the efforts of 'heroic' workers to prevent further meltdown, placed blame on the 'villainOus' TEPCO, and honoured the stoic resilience of the Japanese people; and (4) cancer and contamination, which identified Japan's vulnerable populations and specific health risks, discussed food and water safety, and included coverage on screening practices and detection of radiation.

\section{Discussion and implications}

The media coverage of the Fukushima disaster and its crisis response could have been categorized into environment, human interest, political, economic, and, to a lesser extent, criminal frames (Houston et al., 2012). Stories were also framed to question attribution of responsibility, conflict and morality in the crisis response (An \& Gower, 2009). However, to describe the Fukushima disaster according to these broad frames alone does not help to contextualize subsequent shifts in public opinion and policy within the larger issue culture that shapes and reflects ongoing media discourse related to nuclear power (Gamson \& Modigliani, 1989). In other words, studying the ways in which news frame crises can provide a context by which to understand shifts in public opinion and policy. Previous research has shown that the media's ability to frame the crisis, its causes, and those responsible for its management can influence how audiences interpret and respond to these events (Entman, 1993; Ryan et al., 2001; Van Gorp, 2007; ). In the following discussion, we examine the specific frames that characterized US evening news coverage of the Fukushima disaster to assess how this coverage reflected and contributed to existing media discourse about nuclear issues (Gamson \& Modigliani, 1989) and outline implications for framing theory and crisis management research and practice. Recent discussions of the crisis at Fukushima that found themes consistent with those that emerged in our analysis are included (Aldrich, 2012; Blankson, Nastasia, \& Liu, 2012). 
First, the localizing of coverage reflected existing, and possibly influenced additional, questions regarding the future of US nuclear power. Because foreign crises are not directly experienced by viewers overseas, international stories are often framed for a domestic audience 'by casting far-away events in frameworks that render these events comprehensible' (Gurevitch, Levy, \& Roeh, 1991, 206). The most common theme within the localization frame focused on the safety of the 104 nuclear reactors in the US media reports questioning whether a crisis similar to Fukushima could occur in the United States spurred nuclear critics and temporarily silenced supporters of President Obama's February 2010 proposal to increase federal loan guarantees by $\$ 36$ billion to encourage the start-up of nuclear power plants and launch a 'nuclear renaissance' (Shear \& Mufson, 2010; Schlesinger, 2011). While Obama continued to support the proposal, Congress cited constituent concerns for nuclear safety. The Chairman of the US Nuclear Regulatory Commission argued that 'There is still more work to be done to ensure that lessons learned from [Fukushima] are engrained in the reactor design [...] I cannot support this licensing as if Fukushima never happened' (MSNBC, 2012: paragraph 3). In February 2014, the White House moved forward with plans to build the first reactors in the United States in nearly 30 years. Environmental groups criticized the decision, citing the upcoming third-year anniversary of the events at Fukushima as evidence that nuclear reactors can never be safe. However, the Obama administration argued that nuclear power was necessary to combat climate change (Geewax, 2014).

We suggest that how the media framed the crisis reflected ongoing discourse related to nuclear power and helped to provide additional interpretations for relevant nuclear events that were influential in delaying the still-controversial nuclear renaissance. The media became the primary arena for the frame competition that occurred within stories as the Fukushima disaster 'stimulated public debate' over nuclear energy policies in the United States and in other industrialized nations (Sellnow \& Seeger, 2013, 8). Network news coverage of Fukushima lacked clear progress frames characterizing the domestic necessity of nuclear power in the month following the crisis. Instead, the runaway potential of nuclear technology to cause similar incidents in the United States was heavily emphasized. Therefore, as media attention towards nuclear issues intensified in the month following the Fukushima crisis, we speculate that audiences' existing fatalism and ambivalence towards nuclear power dipped into opposition, which influenced and reflected the larger issue culture that led to the delayed nuclear renaissance. However, even following destabilizing crises, policy reforms in pluralistic nations typically end up being minor or incremental in nature (Boin et al., 2009). Historically, audience opposition towards nuclear development has reverted back to its original ambivalence as media attention towards nuclear issues fades (Gamson \& Modigliani, 1989). This lack of continued media attention paved the way for the reintroduction of government progress frames emphasizing the environmental necessity of nuclear development in the United States. As antinuclear advocates cited the crisis at Fukushima to emphasize the runaway nature of nuclear power, devil's bargain frames characterizing resignation to the inevitable danger of nuclear development have become more prominent in recent news discourse (e.g., Walsh, 2014). Therefore, the existing issue culture that first prevented and has now enabled the resurgence of the nuclear renaissance was likely shaped by and reflected in this shifting media discourse (Gamson \& Modigliani, 1989).

Second, US network news presented conflicting themes characterizing radiation fears, which not only reflected anxiety about the runaway nature of nuclear power that already existed in the larger issue culture, but also created and failed to reduce additional uncertainty that became legitimized in the global marketplace. During Fukushima, worldwide media exposure helped keep the rest of the world informed, engaged, and aware of the complex and rapidly evolving crisis (Blankson et al., 2012). This coverage also served as a focal point for many industrialized nations to reassess their own commitments to nuclear power (Aldrich, 2012). As foreboding images of explosions releasing plumes of radiation, scores of Geiger counters and radiation suits, and empty Japanese neighbourhoods were disseminated in the immediate aftermath of the crisis, news coverage likely tapped into the existing public fear regarding the runaway nature of nuclear energy. Because public and media discourse interact with one another as parallel systems (Gamson \& Modigliani, 1989), subsequent coverage characterized the emotional toll of the crisis by including themes about the anxiety and fear felt by Japanese and American citizens. Stories included the increased purchasing of iodine tablets in the United States, the decrease in foreign imports from Japan, and Japanese citizens abandoning domestic food products. However, the media also frequently attempted to quash concerns regarding the spread of dangerous radiation from Fukushima. For example, 'reality checks' on background radiation were used to compare trace amounts of contaminant detected in America and even Tokyo to radiation in a microwave or banana. Nevertheless, conflicting themes within stories both characterized and attempted to dispel public fear. Because these fears were felt in the global marketplace for an extended period of time, this coverage did not reduce the audience's uncertainty of the crisis to a sufficient degree. Just as disaster coverage influences public perception of the world as more crisis 
prone (James, 2008), the media's inability to dissuade myths concerning disaster behaviour can influence organizational, governmental and public responses to calamity (Tierney, Bevc, \& Kuligowski, 2006). A lesson learned from the coverage of the Fukushima disaster is that, regardless of the media's safety assurances, corporations and nations with the means and policy flexibility to reduce reliance on a potentially dangerous source will pursue other options when fear themes are also present within frames.

Third, our analysis revealed that themes of the fluctuating crisis events changed substantially as the situation unfolded. For example, almost as quickly the situation seemed to be under control, new complications of the crisis would consistently arise. This oscillation contributed to the fundamental runaway characterization of the crisis events at Fukushima as unpredictable, constantly changing, nightmarish and desperate. Journalists and crisis actors were on pins and needles, resigned to an out-of-control technology that betrayed its creators, a time bomb that could explode at any moment and release harmful radiation that could cause invisible and delayed health effects. However, in addition to the rapid evolution of the situation, the uncertainty reduction needed for crisis managers in the early stages of the crisis was lacking (Li, 2007). Frame conflicts regarding the severity of the event were apparent within stories as US news frequently used US government and international nuclear experts to undercut information from TEPCO and the Japanese government, who lost credibility as crisis managers due to their lack of transparency and unwillingness to involve the international community (Buus et al., 2006). Thus, the media could not fulfill their uncertainty reduction duties in the immediate stages of the crisis due in part to Japan's poor crisis response.

A lack of collaboration between emergency officials in Japan and the US media could have also contributed to a lack of uncertainty reduction (Veil, 2012). Much of the coverage failed to include experts and officials from Japan. In fact, PBS was the only station that consistently included Japanese sources as experts and not only affected citizens. As Cohen et al. (2008) explained, when 'expert' voices are marginalized by journalists who emphasize the role of lay parties, the dissemination of accurate information about the scientific and technical aspects of crises often does not occur. In this case, US experts were able to provide insight into the scientific and technical aspects of the crisis, and they did so in great detail, often including complicated computer models of the reactors. However, these experts could only speculate on what was happening inside Fukushima and the implications of the recovery efforts, and that speculation was based on fairly subjective interpretations of science. Different experts also interpreted the situation differently and had contradictory opinions about what could happen. So, while there was not a dearth of scientific and technical information, rather than reducing uncertainty, journalistic source selection and the complicated and sometimes contradictory information presented actually hindered sensemaking and added to public confusion.

Finally, the media shape and reflect how the public perceives the effectiveness of crisis management strategies (Zoeteman et al., 2010). Public accountability frames were used by US news to characterize TEPCO and government officials as failing to take the proper safety precautions necessary to prevent and manage the crisis; neglecting to issue clear and timely information to Japanese citizens, officials and international nuclear crisis actors; ignoring offers of international assistance; and as being largely responsible for rising citizen distrust, anger, and activism and the possible overreactions of foreign governments in their management of the crisis. While Japanese officials used the media to describe the efforts they were taking to protect citizens from the risks of radiation, and TEPCO recapped the organization's past and future contributions to communities (Blankson et al., 2012), competing frames were issued by critics. Oppositional forces exploited the crisis as a critical opportunity to expose the deficiencies of nuclear development as a whole and to advocate for reform or removal of dysfunctional nuclear policies, leaders and organizational behaviours in Japan.Additionally, because of the perception that TEPCO and the Japanese government failed to prevent a controllable crisis and execute an effective disaster response, the level of focused blame issued by critics in the media was maximized (Boin et al., 2009). The history of cover-ups at TEPCO and longstanding government acquiescence to the nuclear industry in Japan also prevented the crisis actors from deploying any pre-existing credibility to disprove rumours and outrage (Zoeteman et al., 2010). Although TEPCO and the Japanese government issued multiple apologies throughout the crisis, blame levels can rise even further in the media when crisis actors under direct blame assume responsibility for their transgressions (Resodihardjo, van Eijk, \& Carroll, 2012). Additionally, the frequent safety assurances and less conservative evacuation zones issued by Japanese officials compared with American officials in the initial days appeared to raise suspicion among the news media. When authorities take an overly calming perspective and do not acknowledge which uncertainties exist, competing risk frames could be amplified (Zoeteman et al., 2010).

We argue that the vilification of TEPCO and the Japanese government was based on culturally discrepant news framing (Feng et al., 2012). Like the US media, the Fukushima Nuclear Accident Independent Investigation, commissioned by the Japanese parliament, declared the disaster 'man-made' and outlined 'errors 
and willful negligence ... and a flawed response' by TEPCO and the Japanese government (Wakatsuki \& Mullen, 2012: paragraphs 1-2). However, the commission also cited the Japanese collectivist culture and 'reluctance to question authority' as an underlying cause of the crisis (Tabuchi, 2012: paragraph 16). Individual culprits were not named because the commission determined the same crisis could have happened with different individuals in the same positions because of the Japanese culture. The primary focus of the report was on instructive findings and recommendations for the future of nuclear energy in Japan. And, despite the intensely critical coverage of TEPCO and the Japanese government, Japan has recently proposed reopening the country's nuclear plants (Walsh, 2014). The resilience of nuclear energy in Japan aligns with the resilience of the Japanese people following the disaster. The Japanese emphasis on collectivism, high power distance and group solidarity may have encouraged news coverage in Japan to be less critical to avoid disturbing the harmony and interests of their society (Blankson et al., 2012). The culture supports a collective move forward.

Conversely, in the frame competition between US and Japanese crisis response perspectives, network news coverage perpetuated the general mythos of the United States as a benevolent hero and all-knowing watchdog who comes to the aid of needy others. Hook and Pu $(2006,178)$ argued that the roots of media framing lie deeper than government regime type and extend to cultural schemas and social identities'. The frames that the US government and media constructed to describe Japan reflected the nature of the relationship between the nations as it has evolved since World War II (Lim et al., 2009). News frames employ larger cultural themes to make coverage appear more natural and familiar to domestic audiences (Gamson \& Modigliani, 1989). Since 9/11, America has assumed a specific, postmodern national identity that 'establishes its own moral virtue through victimization and heroic restitution' (Anker, 2005, 25). US network news portrayed America as unified and virtuous in their response to the nuclear crisis as well as possessing better information, better strategies, and a more open and honest approach than the Japanese government agencies and engineers. Just as US citizens can go online to watch the news on Al Jazeera and the $B B C$, so too can individuals in other countries interested in US news coverage. There is a reason why the United States maintains a reputation as 'Arrogant Americans'. The stereotype is perpetuated on the evening news.

According to Anderson (1992, p. 356), 'The human condition is lived in the semiotic frames that we, the collective, build and support'. The frames presented by the US network news questioned the safety of US nuclear power in the midst of Japan's nuclear crisis and attempted to quell domestic radiation fears while simultaneously presenting the US nuclear industry and government as more intelligent and honest than the Japanese industry and government. We contend that the reality constructed by these interpretations reflects and influences how audiences understand US policies on nuclear power and Japan's ability to recover from the crisis. Our findings also demonstrate how audience perceptions of health risks can endure and influence behaviour, despite the media's attempts to debunk panic myths. This study took a much-needed step beyond the simple identification and quantification of media frames to examine how news framing of international events can help us understand the shift in US public opinion and policy within the context of ongoing US media discourse related to nuclear power. Future research may expand these findings by studying additional international news sources, such as Japanese news broadcasts, in order to compare the international characterizations of the nuclear crisis with the results of our study.

\section{References}

Aldrich, D.P. (2012), 'Post-Crisis Japanese Nuclear Policy: From Top-Down Directives to Bottom-up Activism', Asia Pacific Issues, Volume 103, Pp. 1-10.

An, S.-K. (2011), 'Reducing Anger and Blame: The Role of the Morality News Frame and Crisis Response Strategy', Public Relations Review, Volume 37, Number 2, pp. 169-171.

An, S.-K. and Gower, K.K. (2009), 'How Do the News Media Frame Crises? A Content Analysis of Crisis News Coverage', Public Relations Review,Volume 35, Number 2, pp. 107-112.

Anderson, J.A. (1992), 'Standpoint: On the Ethics of Research in a Socially Constructed Reality', Journal of Broadcasting \& Electronic Media, Volume 36, Number 3, pp. 353-357.

Anker, E. (2005), 'Villains,Victims and Heroes: Melodrama, Media, and September 11', Journal of Communication, Volume 55, Number 1, pp. 22-37.

Blankson, I.A., Nastasia, S. and Liu, M. (2012), 'A Triple Disaster in One Fell Swoop: Rethinking Crisis Communication in Japan after March 11', in George, A. M. and Pratt, C. B. (eds), Case Studies in Crisis Communication: International Perspectives on Hits and Misses, Routledge, New York, pp. 196-226.

Boin, A., Hart, P. and McConnell, A. (2009), 'Crisis Exploitation: Political and Policy Impacts of Framing Contests', Journal of European Public Policy, Volume 16, Number 1, pp. 81-106.

Butler-Kisber, L. (2010), Qualitative Inquiry:Thematic, Narrative, and Arts-Informed Perspectives, Sage, London.

Buus, S. and Olsson, E.-K. (2006), 'The SARS Crisis:Was Anybody Responsible?', Journal of Contingencies \& Crisis Management, Volume 14, Number 2 , Pp. 71-81.

Cho, S.H. and Gower, K.K. (2006), 'Framing Effect on the Public's Response to Crisis: Human Interest Frame and Crisis Type Influencing Responsibility and Blame', Public Relations Review, Volume 32, Number 4, pp. 420-422.

CNN (2011a), Widespread Destruction from Japan Earthquake, Tsunamis, http:// articles.cnn.com/2011-03-11/world/japan.quake_1_hokkaido-tsunami-east -japan-railway?_s=PM:WORLD (accessed 30 October, 2011).

CNN (2011b), 3 Nuclear Reactors Melted Down after Quake, Japan Confirms, http://articles.cnn.com/2011-06-06/world/japan.nuclear.meltdown_1_nuclear -reactors-fuel-rods-tokyo-electric-power?_s=PM:WORLD (accessed 30 October 2011).

Cohen, E.L., Vijaykumar, S., Wray, R. and Karamehic-Muratovic, A. (2008), 'The Minimization of Public Health Risks in Newspapers after Hurricane Katrina', Communication Research Reports, Volume 25, Number 4, Pp. 266281.

Coombs, W.T. and Holladay, S.J. (2010), 'Examining the Effects of Mutability and Framing Perceptions of Human Error and Technical Error Crises: Implications for Situational Crisis Communication Theory', in Coombs, W.T. and 
Holladay, S.J. (eds), Handbook of Crisis Communication, Wiley-Blackwell, New York, pp. 257-274.

Entman, R.M. (1993), 'Framing: Toward Clarification of a Fractured Paradigm', Journal of Communication, Volume 43, Number 4, pp. 51-58.

Feng, M., Brewer, P.R. and Ley, B.L. (2012), 'Framing the Chinese Baby Formula Scandal: A Comparative Analysis of U.S. and Chinese News Coverage', Asian Journal of Communication, Volume 22, Number 3, pp. 253-269.

Gamson, W.A. (1989), 'News as Framing', American Behavioral Scientist, Volume 33, Number 2, pp. 157-161.

Gamson, W. and Modigliani, A. (1989), Media discourse and public opinion on nuclear power: A constructionist approach. American Journal of Sociology, Volume 95, pp. 1-37.

Geewax, M. (2014), 'U.S. Government Will Back Loans for Nuclear Power', National Public Radio, http://www.npr.org/blogs/thetwo-way/2014/02/19/ 279630881/u-s-government-will-back-loans-for-nuclear-power (accessed 19 February 2014).

Gurevitch, M., Levy, M. and Roeh, I. (1991), 'The Global Newsroom: Convergences and Diversities in the Globalisation of Television News', in Dahlgren, P. and Sparks, C. (eds), Communications and Citizenship:Journalism and the Public Sphere in the New Media Age, Routledge, London, pp. 195-215.

Guskin, E., Rosenstiel, T. and Moore, P. (2011), 'State of the News Media, 2011', Pew Research Center, http://stateofthemedia.org/2011/network-essay/datapage-5/ (accessed 21 October 2011).

Harry, B., Sturgis, K.M. and Klingner, J.K. (2005), 'Mapping the Process: An Exemplar of Process and Challenge in Grounded Theory Analysis', Educational Researcher, Volume 34, Number 3, pp. 3-13.

Heath, R.L. and O'Hair, H.D. (eds) (2009), Handbook of Risk and Crisis Communication, Routledge, New York.

Hook, S.W. and Pu, X. (2006), 'Framing Sino-American Relations under Stress:A Reexamination of News Coverage of the 2001 Spy Plane Crisis', Asian Affairs: An American Review, Volume 33, Number 3, pp. 167-183.

Houston, J.B., Pfefferbaum, B. and Rosenholtz, C.E. (2012), 'Disaster News: Framing and Frame Changing in Coverage of Major U.S. Natural Disasters, 2000-2010', Journalism \& Mass Communication Quarterly, Volume 89, Number 4, pp. 606-623.

James, R.K. (2008), Crisis Intervention Strategies, (6th edn), Brooks-Cole/ Thompson, Belmont, CA.

Jones, J.M. (2010), 'U.S. Support for Nuclear Power Climbs to New High of 62\%', Gallop, http://www.gallup.com/poll/126827/support-nuclear-power-climbsnew-high.aspx (accessed 30 October 2011).

Joye, S. (2010), 'News Media and the (De)construction of Risk: How Flemish Newspapers Select and Cover International Disasters', Catalan Journal of Communication \& Cultural Studies, Volume 2, Number 2, pp. 253-266.

Kim, H.J. and Cameron, G.T. (2011), 'Emotions Matter in Crisis: The Role of Anger and Sadness in the Publics' Response to Crisis News Framing and Corporate Crisis Response', Communication Research, Volume 38, Number 6 , pp. 826-855.

Larsson, L. (2010), 'Crisis and Learning', in Coombs, W.T. and Holladay, S.J. (eds), Handbook of Crisis Communication, Wiley, Malden, MA, pp. 713-717.

$\mathrm{Li}, \mathrm{X}$. (2007), 'Stages of a Crisis and Media Frames and Functions: U.S. Television Coverage of the 9/11 Incident during the First 24 Hours', Journal of Broadcasting \& Electronic Media, Volume 51, Number 4, pp. 670-687.

Lim, J. and Seo, H. (2009), "Frame Flow between Government and the News Media and Its Effects on the Public: Framing of North Korea', International Journal of Public Opinion Research, Volume 21, Number 3, Pp. 204-223.

Littlefield, R.S. and Quenette, A.M. (2007), 'Crisis Leadership and Hurricane Katrina: The Portrayal of Authority by the Media in Natural Disasters', Journal of Applied Communication Research, Volume 35, Number 1, Pp. 26-47.

Luther, C.A. and Zhou, X. (2005), 'Within the Boundaries of Politics: News Framing of SARS in China and the United States', Journalism \& Mass Communication Quarterly, Volume 82, Number 4, pp. 857-872.

Masters, A. and Hart, P. (2012), 'Prime Ministerial and Recession Politics: Meaning Making in Economic Crisis Management', Public Administration,Volume 90, Number 3, pp. 759-780.

Miller, M.M. and Riechert, B.P. (2001), 'The Spiral of Opportunity and Frame Resonance: Mapping the Issue Cycle in News and Public Discourse', in Reese, S.D., Gandy, O.H. and Grant, A.E. (eds), Framing Public Life: Perspectives on Media and Our Understanding of the Social World, Lawrence Erlbaum Associates, Mahwah, NJ, pp. 107-122.

MSNBC (2012), US Licenses First Nuclear Reactors Since 1978, http://usnews.msnbc.msn.com/_news/2012/02/09/10362722-us-licenses-first -nuclear-reactors-since-1978 (accessed 8 March 2012).
Muschert, G.W. and Carr, D. (2006), 'Media Salience and Frame Changing across Events: Coverage of Nine School Shootings, 1997-2001', Journalism \& Mass Communication Quarterly, Volume 83, Number 4, pp. 747-766.

Neuendorf, K.A. (2002), The Content Analysis Guidebook, Sage, Thousand Oaks, CA.

Olsson, E.-K. (2010), ‘Defining Crisis News Events', Nordicom Review, Volume 31, Number 1, pp. 87-101.

Pew Research Center (2012). In Changing News Landscape, Even Television is Vulnerable: Trends in News Consumption: 1991-2012, http://www .people-press.org/2012/09/27/in-changing-news-landscape-even-television-is -vulnerable (accessed 27 September 2012).

Reese, S.D. (2001), 'Framing Public Life: A Bridging Model for Media Research', in Reese, S.D., Gandy, O.H. and Grant, A.E. (eds), Framing Public Life: Perspectives on Media and Our Understanding of the Social World, Lawrence Erlbaum Associates, Mahwah, NJ, pp. 7-31.

Resodihardjo, S.L., van Eijk, C.J.A. and Carroll, B.J. (2012), 'Mayor vs. Police Chief: The Hoek van Holland Riot', Journal of Contingencies and Crisis Management, Volume 20, Number 4, pp. 231-243.

Riegert, K. and Olsson, E.-K. (2007), 'The Importance of Ritual in Crisis Journalism', Journalism Practice, Volume 1, Number 2, pp. 143-158.

Ryan, C., Carragee, K.M. and Meinhofer, W. (2001), 'Theory into Practice: Framing, the News Media, and Collective Action', Journal of Broadcasting \& Electronic Media, Volume 45, Number 1, pp. 175-182.

Schlesinger, R. (2011), 'The State of America's Nuclear Effort: Moving beyond Fukushima', Energy Biz, http://www.energybiz.com/magazine/article/243435/ state-america-s-nuclear-effort (accessed 30 October 2011).

Seeger, M.W., Sellnow, T.L. and Ulmer, R.R. (2003), Communication and Organizational Crisis, Praeger, Westport, CT.

Sellnow, T.L. and Seeger, M.W. (2013), Theorizing Crisis Communication, WileyBlackwell, Malden.

Shear, M.D. and Mufson, S. (2010, February 17), Obama offers loan to help fund two nuclear reactors. The Washington Post. http://www.washingtonpost.com/ wp-dyn/content/article/2010/02/16/AR2010021601302.html (accessed 29 October 2014).

Spence, P.R., Westerman, D., Skalski, P.D., Seeger, M., Sellnow, T.L. and Ulmer, R.R. (2006), 'Gender and Age Effects on Information-Seeking after 9/11', Communication Research Reports, Volume 23, Number 3, pp. 217-223.

Strauss, A.L. and Corbin, J. (1998), Basics of Qualitative Research: Grounded Theory Procedures and Techniques, Sage, Newbury Park, CA.

Strömbäck, J. and Nord, L.W. (2006), 'Mismanagement, Mistrust and Missed Opportunities: A Study of the 2004 Tsunami and Swedish Political Communication', Media, Culture, \& Society, Volume 28, Number 5, pp. 789-800.

Tabuchi, H. (2012), 'Inquiry Declares Fukushima Crisis a Man-Made Disaster', The New York Times, http://www.nytimes.com/2012/07/06/world/ asia/fukushima-nuclear-crisis-a-man-made-disaster-report-says.html?_r=0 (accessed 29 October 2014).

Tian, Y. and Stewart, C.M. (2005), 'Framing the SARS Crisis:A Computer-assisted Text Analysis of CNN and BBC Online News Reports of SARS', Asian Journal of Communication, Volume 15, Number 3, pp. 289-301.

Tierney, K., Bevc, C. and Kuligowski, E. (2006), 'Metaphors Matter: Disaster Myths, Media Frames, and Their Consequences in Hurricane Katrina', The Annals of the American Academy of Political and Social Science, Volume 604, pp. 57-81.

Utz, S., Schultz, F. and Glocka, S. (2013), 'Crisis Communication Online: How Medium, Crisis Type and Emotions Affected Public Reactions in the Fukushima Daiichi Nuclear Disaster', Public Relations Review, Volume 39, Number 1, pp. 40-46.

Van Gorp, B. (2007), 'The Constructionist Approach to Framing: Bringing Culture Back In', Journal of Communication, Volume 57, Number 1, pp. 60-78.

Veil, S.R. (2012), 'Clearing the Air: Journalists and Emergency Managers Discuss Disaster Response', Journal of Applied Communication Research, Volume 40, Number 3, pp. 289-306.

Wakatsuki, Y. and Mullen, J. (2012), 'Japanese Parliament Report: Fukushima Nuclear Crisis Was "Man-made"', CNN, http://edition.cnn.com/2012/07/05/ world/asia/japan-fukushima-report/index.html (accessed 29 October 2014).

Walsh, B. (2014), Japan Mulls Nuclear Revival Not Even 3 Years after Fukushima', Time, http://time.com/9684/japan-mulls-nuclear-revival-not-even3-years-after-fukushima/ (accessed 25 February 2014).

Walters, L.M. and Hornig, S. (1993), 'Faces in the News: Network Television News Coverage of Hurricane Hugo and the Loma Prieta', Journal of Broadcasting \& Electronic Media, Volume 37, Number 2, pp. 219-232.

Zoeteman, B.C.J., Kersten, W.C., Vos, W.F., van de Voort, L. and Ale, B.J.M. (2010), 'Communication Management during Risk Events and Crises in a Globalised World', Journal of Risk Research,Volume 13, Number 3, pp. 279-302. 